\title{
Instability of lymphocyte chromosomes in a girl with Rothmund-Thomson syndrome
}

\author{
Karen Helene Örstavik, Noel McFadden, Johan Hagelsteen, Eli Ormerod, Carl Birger \\ van der Hagen
}

\section{Case report}

The patient was born after a normal pregnancy two weeks before term, weight $2500 \mathrm{~g}$, length $45 \mathrm{~cm}$. Multiple malformations were noted immediately. She had a flat face with small palpebral fissures and frontal bossing, a small chin, and small, posteriorly rotated ears (fig 1). She had bilateral radial aplasia, a rudimentary right thumb, and aplasia of the left thumb. The ulnae were short and dysmorphic (fig 2). She also had anal atresia and a rectovaginal fistula. From the age of 3 months skin changes developed on the face and extensor surfaces of the extremities. Erythema, telangiectasia, and hypopigmentation formed a poikiloderma skin pattern in these areas. Her hair was fine with sparse eyebrows. She had the normal number of teeth but several were carious after eruption.

At the age of 18 months she is severely growth retarded $(5 \mathrm{~cm}$ below the 2.5 th centile) Mental development seems to be within normal limits. Since birth there has been a feeding problem, and she is mainly tube fed. Histological examination of a skin biopsy from an affected area of the left thigh showed skin with basal cell degeneration, slight loss of pigment, and non-specific inflammation, consistent with the skin findings of Rothmund-Thomson syndrome.
Department of Medical Genetics, Ullevål University Hospital, 0407 Oslo, Norway

K H Örstavik

E Ormerod

C B van der Hagen

Department of

Dermatology,

Ullevål University

Hospital, Oslo,

Norway

N McFadden

Department of Paediatrics, Ullevå

University

Hospital, Oslo,

Norway

$\mathrm{J}$ Hagelsteen

Correspondence to Dr Örstavik.

Received 19th October 1993

Revised version accepted for publication

17 January 1994 m unidentified marker chr some in eight of a total of 32 cells. A repeat analysis at the age of $10 \mathrm{mont}$ showed three abnormal cells out of 100 analysed: $47, \mathbf{X X},-7,+i(7 q),+7 p, 46, X X$ $t(3 ; 18)(p 14.2 ; q 22)$, and $49, X X,+\operatorname{del}(3)$ (p11.2), + mar, + mar. A skin biopsy from an affected area showed poor growth and five of 48 cells analysed had structural abnormalities. The father had one of 48 cells with an additional marker chromosome and two cells with different $7 ; 14$ translocations. The abnormal chromosome complements in lymphocytes indicate that there may be in vivo chromosome instability in Rothmund-Thomson syndrome.

\section{( $\mathcal{P}$ Med Genet 1994;31:570-572)}

Rothmund-Thomson syndrome is a rare autosomal recessive syndrome characterised by poikiloderma of the face and extremities, alopecia, short stature, and skeletal defects. Only one patient has previously been reported with lymphocyte chromosome abnormalities. The latter patient had trisomy 8 in $2.5 \%$ of peripheral lymphocytes and similarities in phenotype between Rothmund-Thomson syndrome and trisomy 8 mosaicism were underlined. ${ }^{1}$ Another patient had normal lymphocyte chromosomes but clonal lines of aneuploid cells in cultured fibroblasts. ${ }^{2}$ We report here a patient with Rothmund-Thomson syndrome who showed instability of both lymphocyte and fibroblast chromosomes.
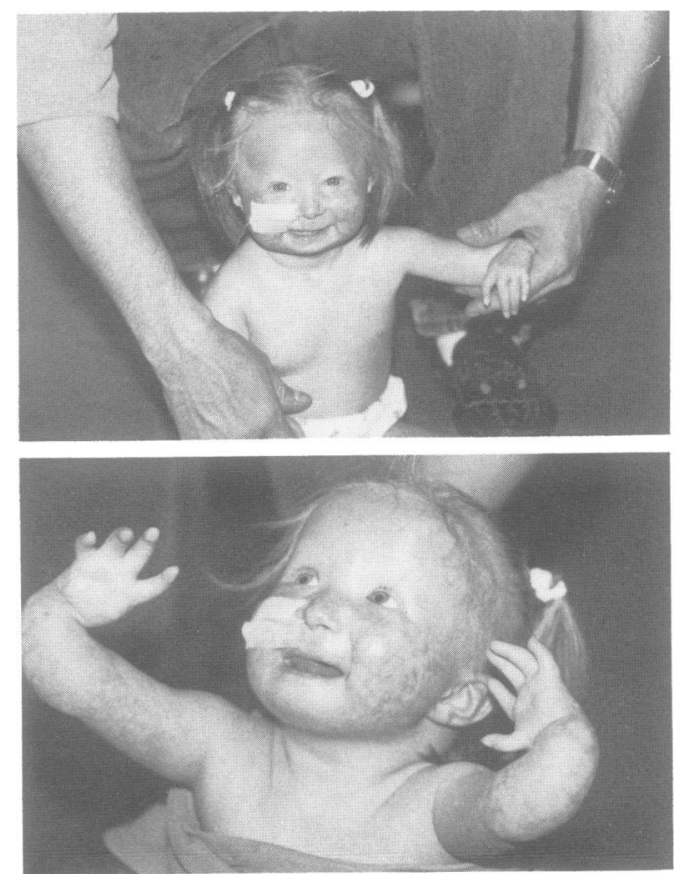

Figure 1 The patient aged 10 months. 

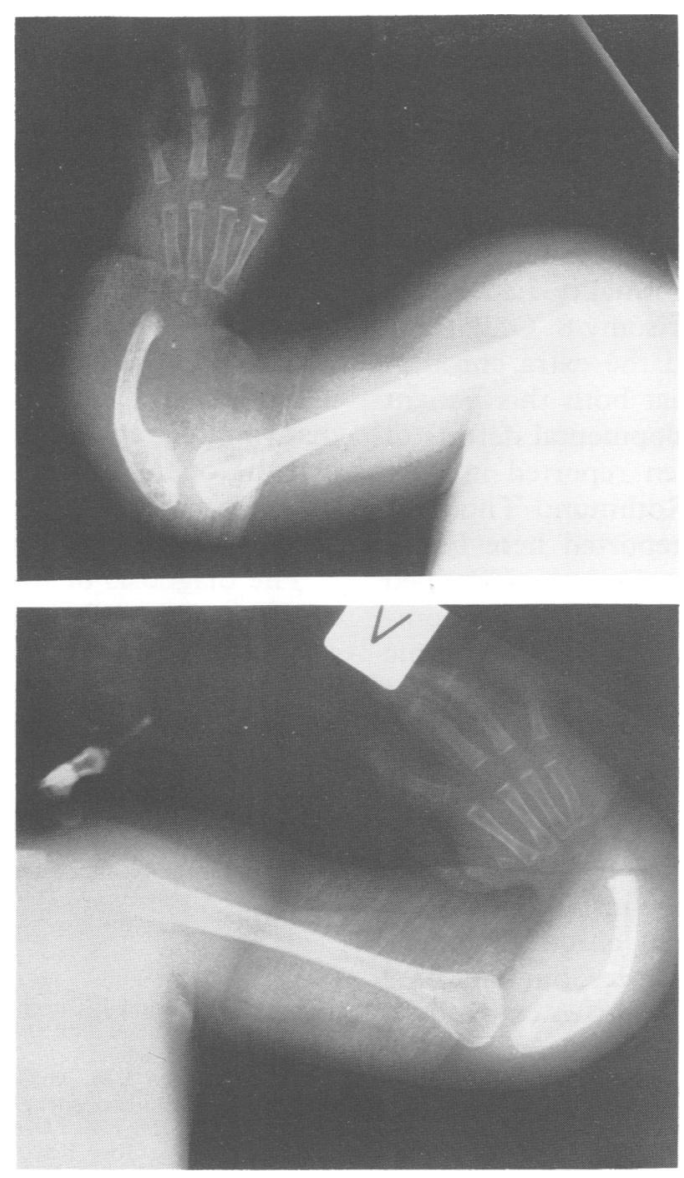

Figure 2 Radiographs of the upper extremities. Note absence of radii and dysmorphic ulnae. Above: right side. Below: left side.

Table 1 Lymphocyte chromosomes in Rothmund-Thomson patient

\begin{tabular}{lll}
\hline Age & Anomalies & No \\
\hline 2 days & $47, \mathrm{XX},+\operatorname{mar}$ & $8 / 32$ \\
9 months & $47, \mathrm{XX},-7,+\mathrm{i}(7 \mathrm{q}),+7 \mathrm{p}$ & $1 / 100$ \\
& $46, \mathrm{XX}, \mathrm{t}(3 ; 18)(\mathrm{p} 14.2 ; \mathrm{q} 22)$ & $1 / 100$ \\
& $49, \mathrm{XX},+\operatorname{del} 3(\mathrm{p} 11.2),+$ mar,+ mar & $1 / 100$ \\
\hline
\end{tabular}

Table 2 Fibroblast chromosomes in Rothmund-Thomson patient

\begin{tabular}{lll}
\hline Age & Anomalies & No \\
\hline 9 months & $47, \mathrm{XX},+\operatorname{mar}$ & $1 / 100$ \\
& $47, \mathrm{XX},+\operatorname{mar}$ & $1 / 100$ \\
& $47, \mathrm{XX},+\mathrm{i}(14 \mathrm{q})$ & $1 / 100$ \\
& $46, \mathrm{XX},-6,+\operatorname{del}(6 \mathrm{q})$ & $1 / 100$ \\
& $46, \mathrm{XX},-2,+\operatorname{del}(2 \mathrm{q})$ & $1 / 100$ \\
\hline
\end{tabular}

Table 3 Lymphocyte chromosomes in the father of Rothmund-Thomson patient

\begin{tabular}{ll}
\hline Anomalies & No \\
\hline $47, \mathrm{XY},+\operatorname{mar}$ & $1 / 48$ \\
$46, \mathrm{XY}, \mathrm{t}(7 ; 14)(\mathrm{p} 13 ; \mathrm{q} 11.2)$ & $1 / 48$ \\
$46, \mathrm{XY}, \mathrm{t}(7 ; 14)(\mathrm{q} 36 ; \mathrm{q} 11.2)$ & $1 / 48$ \\
\hline
\end{tabular}

The parents are healthy and unrelated but come from the same small rural area. The father was 26 years and the mother 37 years old. The mother has a healthy son and daughter by a previous marriage. There are no congenital malformations in the immediate family.

\section{Methods}

Lymphocytes were cultured in medium 199 supplemented with $6 \%$ fetal bovine serum (FBS) (Gibco, Grand Island, NY) and 1\% antibiotics (Gibco: penicillin $5000 \mathrm{U} / \mathrm{ml}$, streptomycin $5000 \mu \mathrm{g} / \mathrm{ml}$ ). Colcemid was added one hour before harvesting.

Fibroblasts were cultivated in medium 199 supplemented with $10 \%$ Chang medium (Irvine Scientific), 20\% human AB serum, and $2 \%$ antibiotics (Gibco). The cells were subcultivated in Chang medium. Colcemid was added 40 minutes before harvesting.

Metaphases were stained with GTG banding. Fluorescence in situ hybridisation (FISH) was performed with a chromosome 8 specific painting probe from Gibco.

\section{Results}

Lymphocyte chromosomes in the neonatal period showed an unidentified marker in eight of a total of 32 cells examined. Since mosaicism for chromosome 8 has been reported in Rothmund-Thomson syndrome, ${ }^{1}$ a FISH technique was used with a chromosome 8 specific probe. However, the marker chromosome could not be identified as a chromosome 8 . A repeat analysis at the age of 10 months showed three abnormal lymphocytes out of 100 analysed (table 1). No increase in breakage was found.

A skin biopsy from an affected area showed extremely poor growth. The cells were subcultured five times before harvesting. Five of 100 cells examined showed structural anomalies, including two cells with an extra marker chromosome (table 2).

Lymphocyte chromosomes of the mother were normal, whereas three of 48 cells examined from the father showed abnormalities. One cell had a marker chromosome, and the other two cells had a 7;14 translocation (table $3)$.

\section{Discussion}

Rothmund-Thomson syndrome was first described by the Swiss ophthalmologist Rothmund, ${ }^{3}$ and later by the British dermatologist Thomson. ${ }^{4}$ Two hundred patients have been reported and recently reviewed. ${ }^{5}$ The patient reported here has the characteristic features of Rothmund-Thomson syndrome, including the cutaneous manifestations, skeletal abnormalities, severe growth retardation, and facial features. However, the patient also had anal atresia with a rectovaginal fistula. Gastrointestinal malformations seem to be rare in Rothmund-Thomson syndrome. Roth et $a l^{6}$ described a girl with an anteriorly placed stenotic anus, and Blaustein $e t$ al reported a boy with annular pancreas and duodenal stenosis.

Der Kaloustian et $a l^{2}$ reported a patient with 
normal lymphocyte chromosomes and clones of cytogenetically abnormal fibroblasts, including one clone of trisomy 8 cells, and several clones of cells with various structural rearrangements. They concluded that these changes were the result of in vitro events.

The previously reported patient with a lymphocyte chromosome abnormality had a low frequency mosaicism for trisomy 8 . Only three of 125 cells examined had the extra chromosome. ${ }^{1}$ It is interesting that both this patient and our patient have developmental defects of the radius, which has been reported in only $10 \%$ of patients with Rothmund-Thomson syndrome. ${ }^{5}$ The patient reported here had a higher frequency mosaicism for an unidentified fragment. The frequency of Rothmund-Thomson patients with a lymphocyte chromosome abnormality may be higher, since it is likely that chromosome abnormalities are overlooked in patients with a low frequency mosaicism. The report of two patients with lymphocyte chromosome abnormalities may indicate that patients with Rothmund-Thomson syndrome have an in vivo chromosome instability.

The father has no clonal chromosome rearrangements in his lymphocytes, but had three abnormal cells. Two cells had two of the 7;14 translocations occasionally found in routine chromosome investigations. The chromosome findings in the father may be a chance occurrence. However, it is very rare to observe two different 7;14 translocations in the same person. Further studies are necessary to establish whether there is a chromosome instability also in heterozygotes for Rothmund-Thomson syndrome.

Rothmund-Thomson syndrome has many features in common with the classic chromosome instability syndromes: ataxia telangiectasia, Bloom's syndrome, Fanconi's anaemia, and xeroderma pigmentosum. The aplastic radii are seen in Fanconi's anaemia, and the skin changes, the tendency to malignancy, and the extreme growth retardation are found in all four syndromes. The finding of lymphocyte chromosome instability in two patients with Rothmund-Thomson syndrome indicates further similarities between this syndrome and the classic instability syndromes. In the recent review of Vennos et al, ${ }^{5}$ it was suggested that Rothmund-Thomson syndrome might represent a variable repression of DNA repair genes resulting in increased sensitivity to carcinogens, and that variable repression of developmental genes may be operating in parallel. Reduced DNA repair capacity was recently found in a 5 year old boy with Rothmund-Thomson syndrome. ${ }^{8}$

The diagnosis of Rothmund-Thomson syndrome is difficult before the development of the erythema. The finding of a chromosome anomaly before the erythema develops may lead to a wrong diagnosis and incorrect genetic counselling.

A fibroblast derived cell line from the patient with identification number F 1992 is available from the first author. We acknowledge the assistance of the Department of Radiology, Ulleval Hospital.

1 Ying KL, Oizumi J, Curry CJR. Rothmund-Thomson syndrome associated with trisomy 8 mosiacism. $\mathcal{F}$ Med Genet 1990;27:258-60.

2 Der Kaloustian VM, McGill JJ, Vekemans M, Kopelman HR. Clonal lines of aneuploid cells in Rothmund-Thomson syndrome. Am $\mathcal{F}$ Med Genet 1990;37:336-9.

3 Rothmund A. Uber Katarakten in Verbindung mit einer eigentumlichen Hautdegeneration. Alb Gr Arch Klin Ophthalmol 1868;14:159-82.

4 Thomson MS. An hitherto undescribed familial disease. $B r \mathcal{F}$ Dermatol 1923;35:455-61.

5 Vennos EM, Collins M, James WD. Rothmund-Thomson syndrome: review of the world literature. $\mathcal{F} \mathrm{Am}$ Acad Dermatol 1992;27:750-62.

6 Roth DE, Campisano C, Callen JP, Hersh JH, Yusk JW. Rothmund-Thomson syndrome: a case report. Pediatr Dermatol 1989;6:321-4.

7 Blaustein HS, Stevens AW, Stevens PD, Grossman ME Rothmund-Thomson syndrome associated with annular Rothmund-Thomson syndrome associated with annular pancreas and duodenal sten

8 Shinya A, Nishigori C, Moriwaki S, et al. A case of Rothmund-Thomson syndrome with reduced DNA repair capacity. Arch Dermatol 1993;129:332-5. 